\title{
Integrated Process of Obtaining Heat and Silicon(IV) Oxide from Siliceous Plant Materials
}

\author{
D.V. Hura*, P.I. Soroka, A.A. Cheremysinova \\ Technology of high-molecular compounds faculty, Ukrainian State University of Chemical Technology, 49005, Dnipropetrovsk, Ukraine \\ *Corresponding Author: denhyr@mail.ru
}

Copyright (C) 2014 Horizon Research Publishing All rights reserved.

\begin{abstract}
A differential thermal analysis of the process of preliminary prepared rice husk (PPRH) thermal treatment was conducted. The phase composition of the $\mathrm{SiO}_{2}$ samples was investigated and the dispersed composition of $\mathrm{SiO}_{2}$ and PPRH powders obtained as a result of PPRH thermal treatment was studied. The procedure mechanism and kinetic constants of the reactions of thermal transformation of PPRH into silicon(IV) oxide were offered. A mathematical model of the process of obtaining silicon(IV) oxide and thermal energy out of PPRH was developed which includes equations of the transformation kinetic of PPRH into $\mathrm{SiO}_{2}$, heat and mass exchange and also equations of gas dynamics. The process was explored in the mathematical model.
\end{abstract}

Keywords Rice Husk, Thermal Energy, Silicon(IV) Oxide, Mathematical Model

\section{Introduction}

An important ecological problem in the whole world is environmental protection from waste matter, farming industry in particular.

One of such waste products is large-tonnage, constantly renewed waste of rice production - rice husk (RH). About 163 million tons of RH are produced annually in the world. Major countries of waste producers are China (41.27), India (29.41), Indonesia (14.17), Bangladesh (10.50), Vietnam (8.56), Myanmar (7.19), Thailand (6.92), Philippines (3.58), Brazil (2.78), Japan (2.33), Pakistan (2.27) and USA (2.20).[1,2]. Currently this type of farming industry waste treatment is a very important technical problem.

Considering $\mathrm{RH}$ as organic fuel we can talk about additional energy due to thermal effects that accompany the process of obtaining $\mathrm{SiO}_{2}$. It can be considered that carbon and hydrogen contained in $\mathrm{RH}$ are the combustible part and $\mathrm{SiO}_{2}$ is the cinder that is generated during the direct combustion of plant material $[3,4]$.

Today, there are a sufficient number of $\mathrm{RH}$ processing methods with obtaining heat and $\mathrm{SiO}_{2}$. It's known a method of obtaining silica from rice production wastes and device for its implementation [5] which is conducted in the conditions of "clamped layer". The drawbacks of such method are: long period of burning of non-grinded $\mathrm{RH}$, impossibility of providing of even process of combustion within the whole layer of raw material in the conditions of "clamped layer" that results into high carbon content of the final product.

Also there's known a method of obtaining silica and heat energy from plant siliceous wastes [6] which has such drawbacks as low efficiency and economy of obtaining the target product and heat owing to burning $\mathrm{RH}$ in the conditions of compact layer of raw material. In such conditions the diffusion of air, water and gaseous products of combustion through the layer of raw material decreases considerably and flows not even and as a result there occurs irregularity of temperatures through the whole length of the burning zone, the time of RH particles burning increases and the purity of the target product falls down. This method uses non-grinded $\mathrm{RH}$ that raises the time of its thermal treatment.

Therefore, this study aimed to developing method which will be considered and corrected these shortcomings.

\section{Materials and Methods}

With the help of elemental analysis the $\mathrm{RH}$ chemical composition was identified, \% by weight: $\mathrm{SiO}_{2}-22.24, \mathrm{C}-$ $35.77, \mathrm{O}-36.62, \mathrm{H}-5.2, \mathrm{~N}-0.32$ [7]. To study the process of co-production of silicon(IV) oxide and thermal energy PPRH was used. Depending on the method of $\mathrm{RH}$ preparation highly pure [8] or industrial silicon(IV) oxide can be obtained. In this work PPRH was rinsed with distilled water at the temperature $80-90^{\circ} \mathrm{C}$, dried and grinded by a percussive- catoptrical mill [9].

The PPRH heat treatment process was studied with differential thermal analysis (DTA) that was carried out on a derivatograph of «Paulik F.- Paulik J.- Erdey L.» system manufactured in Hungary. PPRH heat treatment was performed in an air atmosphere with the temperature range $20-1000^{\circ} \mathrm{C}$ at sample heating speed $10^{\circ} / \mathrm{min}$.

To determine the phase composition of the products of PPRH thermal processing there was used X-ray diffraction 
(XRD) that was carried out on a computerized diphractometer DRON-2 with upgraded collimation on the filtered $\mathrm{CuK} \alpha$-radiation.

To investigate changes in the particle size and dispersion of the PPRH powder during its heat treatment there was used the scanning electron microscopy (SEM) that allows to work in a wide magnification range from 10 to 1,000,000 fold. The survey was carried out using a scanning electronic microscope SEM-106I in secondary electrons with the boundary residual pressure in the microscope column (in the gun area) not more than $6.7 \cdot 10^{-40} \mathrm{~Pa}\left(5 \cdot 10^{-6} \mathrm{~mm}\right.$. Mercury) and $111 \mathrm{~mA}$ gun current.

\section{Results and Discussion}

Figure 1 shows the results of the DTA. As we can see two endo- $\left(120,950^{\circ} \mathrm{C}\right)$ and two exoeffects $\left(300,450^{\circ} \mathrm{C}\right)$ are recorded on the DTA curve. The endothermic effect at $120^{\circ} \mathrm{C}$ is associated with the removal of free water from the PPRH. The exothermal effect at $300^{\circ} \mathrm{C}$ fixed on the DTA curve is caused by the combustion of cellulose and the exoeffect at $450^{\circ} \mathrm{C}$ - is caused by the process of lignin combustion $[10,11]$. Decomposition of PPRH ends at $800^{\circ} \mathrm{C}$. The weight loss of the PPRH sample on ignition (LOI) is $78 \%$ by weight.

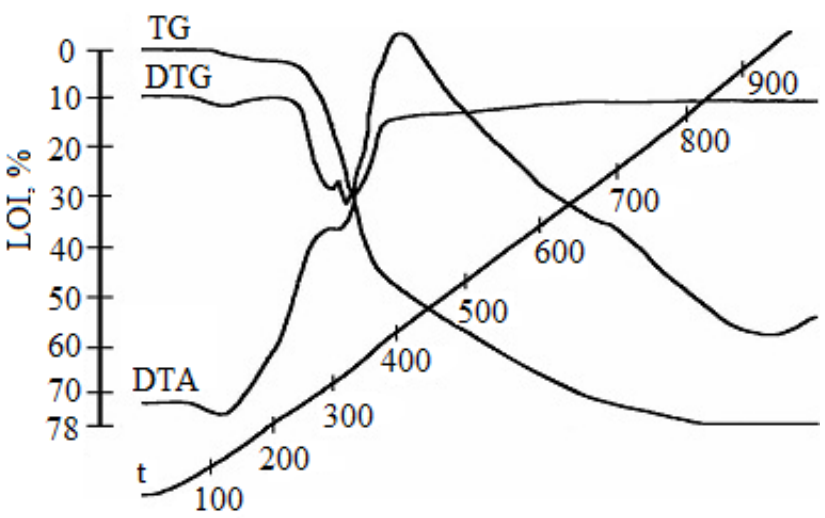

Figure 1. Derivation of PPRH

In Figure 2 we can see the X-ray diffraction patterns of $\mathrm{SiO}_{2}$ samples obtained during PPRH heat treatment at different temperatures. It is clear that after PPRH ignition at temperatures from $500-900^{\circ} \mathrm{C}$ (lines $\left.1-5\right)$ the $\mathrm{SiO}_{2}$ samples are X-ray amorphous since the diffraction patterns of crystalline phase these samples diffraction peaks are not observed.

On the diffraction pattern of $\mathrm{SiO}_{2}$ sample obtained after PPRH heat treatment at $1000^{\circ} \mathrm{C}$ (line 6) we can observe diffraction peaks at $\mathrm{d}_{\mathrm{HKL}}=4.25,3.34,2.48,2.12,1.93,1.67$, $1.54,1.37 \AA$ that correspond $\mathrm{d}_{\mathrm{HKL}}$ for $\mathrm{SiO}_{2}[12]$ that indicates the presence of crystalline phases in the sample.

Thus the exoeffect fixed at $950^{\circ} \mathrm{C}$ (Fig.1) indicates the transition of $\mathrm{SiO}_{2}$ from an amorphous form to crystalline.

The change of PPRH particle diameter in the process of thermal treatment was determined by examining the photomicrographs of PPRH particles (Fig.3.a) and particles of $\mathrm{SiO}_{2}$ obtained by heat treatment of PPRH (Fig.3.b).

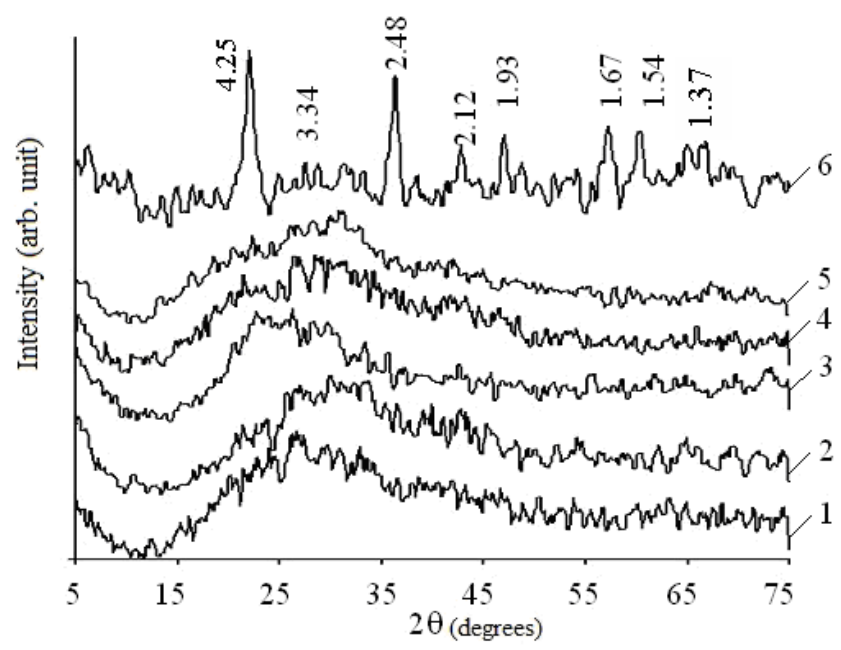

$1-500,2-600,3-700,4-800,5-900,6-1000$.

Figure 2. XRD profiles for $\mathrm{SiO}_{2}$ samples obtained from $\mathrm{PPRH}$ at different temperatures, ${ }^{\circ} \mathrm{C}$ :

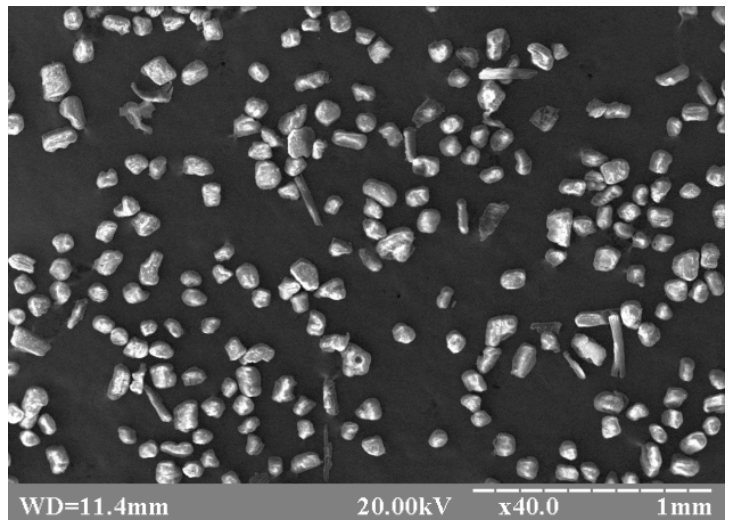

a)

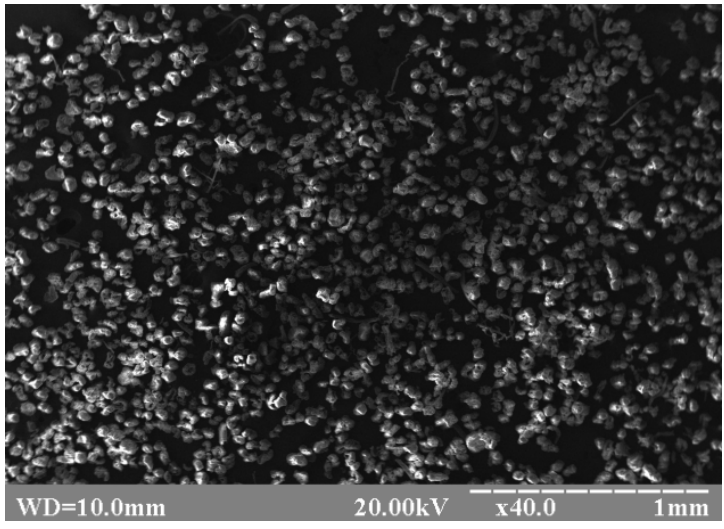

b)

$\mathrm{a}-\mathrm{PPRH}, \mathrm{b}-\mathrm{SiO}_{2}$ obtained from PPRH

Figure 3. Powders photomicrographies

After processing the data derived from photomicrographs of PPRH and $\mathrm{SiO}_{2}$ powders curves of PPRH and $\mathrm{SiO}_{2}$ powders particle size distribution were constructed. Graphs shown in Figure 4. provide a visual representation of the 
particulate composition of the powders of PPRH and $\mathrm{SiO}_{2}$ obtained from PPRH.

Figure 4 shows that in the studied sample of PPRH the biggest amount of particles are with diameter $\delta=100$ microns the percentage of which $\left(\mathrm{N}_{\mathrm{i}}\right)$ is $39.2 \%$ of the total particles counted and in the sample of $\mathrm{SiO}_{2}$ the biggest amount of particles are with diameter $\delta=55,6$ microns the percentage of which is $45,9 \%$. Also, it can be concluded that the particles of PPRH vary in size ranging from 65 to 190 microns, and particles of $\mathrm{SiO}_{2}$ range from 22 to 120 microns.

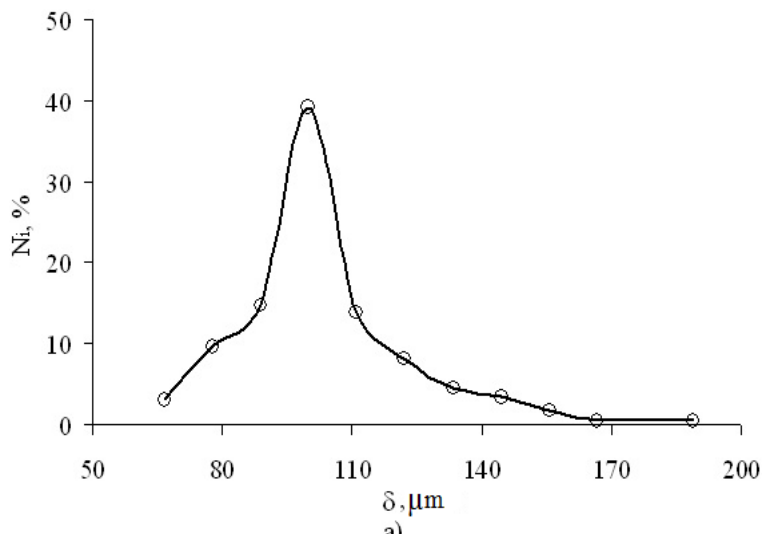

a)

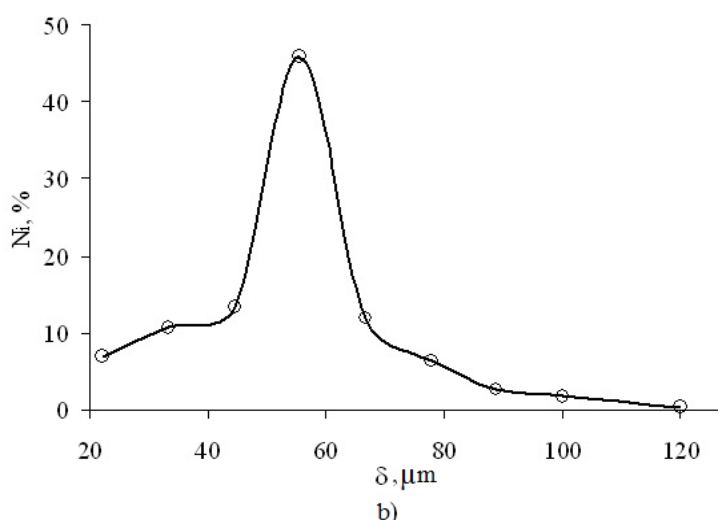

a - PPRH, b - $\mathrm{SiO}_{2}$ obtained from PPRH

Figure 4. The curves of particle size distribution

After studying the data received during thermogravimetric, chemical and phase analyses of PPRH samples mechanisms of PPRH heat treatment reactions with obtaining silicon(IV) oxide were proposed:

$$
\begin{gathered}
\mathrm{C}_{3.08} \mathrm{H}_{5.2} \mathrm{O}_{2.36} \mathrm{~N}_{0.02} \cdot 0.38 \mathrm{SiO}_{2} \cdot 0.42 \mathrm{H}_{2} \mathrm{O} \rightarrow \\
\mathrm{C}_{3.08} \mathrm{H}_{5.2} \mathrm{O}_{2.36} \cdot 0.38 \mathrm{SiO}_{2}+0.42 \mathrm{H}_{2} \mathrm{O}+0.01 \mathrm{~N}_{2} ; \\
\mathrm{C}_{3.08} \mathrm{H}_{5.2} \mathrm{O}_{2.36} \cdot 0.38 \mathrm{SiO}_{2} \rightarrow \mathrm{C}_{1.84} \mathrm{H}_{3.12} \mathrm{O}_{1.34} \cdot 0.38 \mathrm{SiO}_{2}+ \\
1.04 \mathrm{H}_{2} \mathrm{O}+1.24 \mathrm{CO}_{2} ; \\
\mathrm{C}_{1.84} \mathrm{H}_{3.12} \mathrm{O}_{1.34} \cdot 0.38 \mathrm{SiO}_{2} \rightarrow 0.38 \mathrm{SiO}_{2}+ \\
1.56 \mathrm{H}_{2} \mathrm{O}+0.8 \mathrm{CO}_{2}+1.04 \mathrm{CO} .
\end{gathered}
$$

As a result of DTA according to the methodology [13] there were calculated activation energy and pre-exponential factors of reactions (1) - (3) the values of witch are given in Table 1.
Table 1. The values of activation energy and pre-exponential factors of PPRH heat treatment reactions

\begin{tabular}{|c|c|c|}
\hline $\begin{array}{c}\text { Chemical } \\
\text { reaction }\end{array}$ & The pre-exponential factor, $\mathrm{c}^{-1}$ & $\begin{array}{c}\text { The activation } \\
\text { energy of the } \\
\text { reaction, } \\
\text { Joule/mol }\end{array}$ \\
\hline 1 & $1.66 \cdot 10^{3}$ & $39 \cdot 10^{3}$ \\
\hline 2 & $36.70 \cdot 10^{6}$ & $102.97 \cdot 10^{3}$ \\
\hline 3 & $1.79 \cdot 10^{1}$ & $56 \cdot 10^{3}$ \\
\hline
\end{tabular}

On the basis of the proposed mechanism there were drawn 3 differential and 5 algebraic equations of the material balance of the PPRH heat treatment process [14]:

$$
\begin{gathered}
\frac{\mathrm{dn}_{1}}{\mathrm{~d} \tau}=-\mathrm{k}_{1} \mathrm{n}_{1} \\
\frac{\mathrm{dn} \mathrm{n}_{2}}{\mathrm{~d} \tau}=\mathrm{k}_{1} \mathrm{n}_{1}-\mathrm{k}_{2} \mathrm{n}_{2} \\
\frac{\mathrm{dn}}{\mathrm{d} \tau}=\mathrm{k}_{2} \mathrm{n}_{2}-\mathrm{k}_{3} \mathrm{n}_{3} ; \\
\mathrm{n}_{4}=0,01 \mathrm{n}_{1}^{0}-0,01 \mathrm{n}_{1}-0,01 \mathrm{n}_{2} ; \\
\mathrm{n}_{5}=3,02 \mathrm{n}_{1}^{0}-3,02 \mathrm{n}_{1}-2,6 \mathrm{n}_{2}-1,56 \mathrm{n}_{3} ; \\
\mathrm{n}_{6}=1,04\left(\mathrm{n}_{1}^{0}-\mathrm{n}_{3}\right) ; \\
\mathrm{n}_{8}=0,38\left(\mathrm{n}_{1}^{0}-\mathrm{n}_{1}-\mathrm{n}_{2}-\mathrm{n}_{3}\right)
\end{gathered}
$$

where $\mathrm{k}_{1}, \mathrm{k}_{2}, \mathrm{k}_{3}$ are the rate constants of the corresponding chemical reactions, $n_{1}$ - the number of moles of PPRH at the initial time, $n_{i}$ - the number of mol of $i$-th element involved in the reactions (1) - (3) at the current time.

The descriptions of components participating in the reactions (1) - (3) are shown in Table 2.

Table 2. The descriptions of components participating in the reactions of PPRH heat treatment

\begin{tabular}{|c|c|}
\hline Component & Description \\
\hline $\mathrm{C}_{3,08} \mathrm{H}_{5,2} \mathrm{O}_{2,36} \mathrm{~N}_{0,02} \cdot 0,38 \mathrm{SiO}_{2} \cdot 0,42 \mathrm{H}_{2} \mathrm{O}$ & $\mathrm{n}_{1}$ \\
\hline $\mathrm{C}_{3,08} \mathrm{H}_{5,2} \mathrm{O}_{2,36} \cdot 0,38 \mathrm{SiO}_{2}$ & $\mathrm{n}_{2}$ \\
\hline $\mathrm{C}_{1,84} \mathrm{H}_{3,12} \mathrm{O}_{1,34} \cdot 0,38 \mathrm{SiO}_{2}$ & $\mathrm{n}_{3}$ \\
\hline $\mathrm{N}_{2}$ & $\mathrm{n}_{4}$ \\
\hline $\mathrm{H}_{2} \mathrm{O}$ & $\mathrm{n}_{5}$ \\
\hline $\mathrm{CO}$ & $\mathrm{n}_{6}$ \\
\hline $\mathrm{CO}_{2}$ & $\mathrm{n}_{7}$ \\
\hline $\mathrm{SiO}_{2}$ & $\mathrm{n}_{8}$ \\
\hline
\end{tabular}

To develop a mathematical model of the combined process of obtaining heat energy and silicon(IV) oxide from PPRH there was proposed a physical model of the process 
shown in Fig. 5.

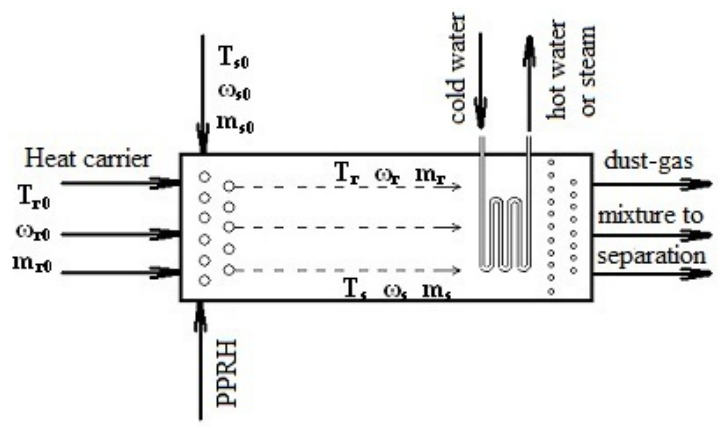

Figure 5. The physical model of the combined process of obtaining heat and silicon(IV) oxide from PPRH

The physical model is a cylindrical reactor, operating on the principle of a plug flow, wherein the PPRH heat treatment process is carried out in a moving stream of dust-gas mixture. According to the approved physical model, heat carrier with an initial temperature of $\mathrm{T}_{\mathrm{r} 0}$, velocity $\omega_{\mathrm{r} 0}$ and mass flow $\mathrm{m}_{\mathrm{r} 0}$ is supplied into the initial section of the reactor, perpendicular to the flow of the heat carrier particles of PPRH with the initial temperature $T_{\mathrm{s} 0}$ velocity $\omega_{\mathrm{s} 0}$ and mass flow $\mathrm{m}_{\mathrm{s} 0}$ are fed. The formed dust-gas mixture moves along the reactor where heat and mass transfer and chemical transformation processes take place. At the end of the heat treatment zone with a help of a heat exchanger, heat recovery of the dust-gas mixture is realized. After that the cooled mixture of dust and gas is separated into a solid target product $\mathrm{SiO}_{2}$ and gaseous products of PPRH heat treatment.

When drawing up the mathematical model the following assumptions were made: the particles are spherical, their volume is negligibly small compared with the volume of the gas phase, the gas obeys the ideal gas law, heat exchange between the heat carrier and the dispersed particles takes place in adiabatic conditions, RH particle velocity in the initial section of the reactor is equal to zero [15].

The basic equations of the mathematical model of the combined process of obtaining heat and silicon(IV) oxide from PPRH to be considered:

The equation of particle motion

The equation of a particle motion is derived from the equations of motion of a solid sphere in a resisting medium [16]:

$$
\frac{\mathrm{d} \omega_{\mathrm{s}}}{\mathrm{d} \tau}=\frac{9 \mathrm{f}_{\mathrm{x}} \mu_{\mathrm{r}}}{2 \mathrm{r}_{\mathrm{s}}^{2} \rho_{\mathrm{s}}}\left(\omega_{\mathrm{r}}-\omega_{\mathrm{s}}\right),
$$

wherein $\omega_{\mathrm{r}}, \omega_{\mathrm{s}}-$ velocity of the heat carrier and the particles in the current section of the reactor, respectively; $r_{s}$ - particle radius in the current section of the reactor; $\rho_{\mathrm{s}}-$ the particle density in the current section of the reactor; $f_{x}$ - resistance function of the particle movement; $\mu_{\mathrm{r}}-$ coefficient of dynamic viscosity of the heat carrier in the current section of the reactor.

The equation of particle heating
The equation of a particle temperature change was obtained by using the equation that describes the convective heat transfer between the particles and the heat carrier [17]:

$$
\frac{\mathrm{dT}_{\mathrm{s}}}{\mathrm{d} \tau}=\frac{3 \mathrm{Nu} \lambda_{\mathrm{r}}}{2 \mathrm{r}_{\mathrm{s}}^{2} \rho_{\mathrm{s}} \mathrm{c}_{\mathrm{s}}}\left(\mathrm{T}_{\mathrm{r}}-\mathrm{T}_{\mathrm{s}}\right),
$$

where $T_{r}$ and $T_{S}$ - respectively are the heat carrier and the particles temperature in the current section of the reactor; $\mathrm{Nu}$ - the Nusselt number that considers rarefaction of the heat carrier flow on the heat transfer rate; $\lambda_{\mathrm{T}}$ - coefficient of the heat carrier thermal conductivity in the current section of the reactor; $\mathrm{c}_{\mathrm{s}}$ - thermal capacity of a particle in the current section of the reactor.

The equation of temperature change of the heat carrier flow

To derive the equation of fluid temperature change there was made up an equation of energy-conservation of the system:

$$
\begin{aligned}
& \mathrm{m}_{\mathrm{r}_{0}}\left(\mathrm{i}_{\mathrm{r}_{0}}+\frac{\omega_{\mathrm{r}_{0}}^{2}}{2}\right)+\mathrm{m}_{\mathrm{s}_{0}}\left(\mathrm{i}_{\mathrm{s}_{0}}+\frac{\omega_{\mathrm{s}_{0}}^{2}}{2}\right)+Q_{\mathrm{H}}^{\mathrm{p}}+\mathrm{Q}_{\mathrm{add}}= \\
& =\mathrm{m}_{\mathrm{r}}\left(\mathrm{i}_{\mathrm{r}}+\frac{\omega_{\mathrm{r}}^{2}}{2}\right)+\mathrm{m}_{\mathrm{s}}\left(\mathrm{i}_{\mathrm{s}}+\frac{\omega_{\mathrm{s}}^{2}}{2}\right)
\end{aligned}
$$

where $\mathrm{m}_{\mathrm{r} 0}-$ is a mass flow rate of the heat carrier in the initial section of the reactor; $\mathrm{i}_{\mathrm{r} 0}-$ enthalpy of the heat carrier in the initial section of the reactor; $\omega_{\mathrm{r} 0}$ - heat carrier velocity in the initial section of the reactor; $\mathrm{m}_{\mathrm{s} 0}$ - mass flow of particles in the initial section of the reactor; $i_{s 0}$ - enthalpy of the particles in the initial section of the reactor; $\omega_{\mathrm{s} 0}$ - particle velocity in the initial section of the reactor; $\mathrm{m}_{\mathrm{r}}, \mathrm{m}_{\mathrm{s}}-$ mass flow of heat carrier and particles in the current section of the reactor; $\omega_{\mathrm{I}}$, $\omega_{\mathrm{s}}$ - velocity of the heat carrier and the particles in the current section of the reactor; $i_{r}$ - enthalpy of the heat carrier in the current section of the reactor; $i_{s}=c_{s} T_{s}-$ enthalgy of the particles in the current section of the reactor; $Q_{\mathrm{H}}-$ the amount of heat released as a result of heat treatment of PPRH;

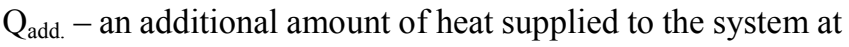
the initial time.

In the temperature range $20-1000^{\circ} \mathrm{C}$ dependence of the heat carrier components enthalpy from the temperature can be approximated by the equation:

$$
\mathrm{i}_{\mathrm{i}}=\mathrm{a}_{\mathrm{i}}+\mathrm{b}_{\mathrm{i}} \mathrm{T}_{\mathrm{r}},
$$

where $a_{i}$ and $b_{i}$ are coefficients of approximation for the $i$-th component of the heat carrier.

Mass flow of the particles and the heat carrier flow in the current section of the reactor can be expressed by the following equations:

$$
\begin{aligned}
& \mathrm{m}_{\mathrm{s}}=\mathrm{m}_{\mathrm{r}_{0}} \mathrm{~W}-\sum \mathrm{n}_{\mathrm{i}} \mathrm{M}_{\mathrm{i}} ; \\
& \mathrm{m}_{\mathrm{r}}=\mathrm{m}_{\mathrm{r}_{0}} \mathrm{~W}+\sum \mathrm{n}_{\mathrm{i}} \mathrm{M}_{\mathrm{i}},
\end{aligned}
$$

where $\mathrm{W}=\mathrm{m}_{\mathrm{s}_{0}} / \mathrm{m}_{\mathrm{r}_{0}}$ - the ratio of mass flow of PPRH particles and the heat carrier in the initial section of the reactor; $n_{i}-$ mole number of the $i$-th gas component obtained 
by the heat treatment of PPRH; $\mathrm{M}_{\mathrm{i}}$ - the molecular weight of the i-th gaseous component; $\Sigma n_{i} M_{i}-$ the mass of gaseous products of the process of thermal decomposition of PPRH.

After substituting expression (12), (13), (14) into the equation (11) and differentiating it we obtain the equation of temperature change of the heat carrier flow:

$$
\begin{aligned}
& \frac{d T_{r}}{d \tau}=\frac{1}{\left(m_{r_{0}}+\sum n_{i} M_{i}\right) b_{i}}\left[\sum M_{i}\left(a_{i}+b_{i} T_{r}+\frac{\omega_{r}^{2}}{2}-c_{s} T_{s}-\frac{\omega_{s}^{2}}{2}\right) \frac{d n_{i}}{d \tau}+\right. \\
& +\omega_{r}\left(m_{r_{0}}+\sum n_{i} M_{i}\right) \frac{d \omega_{r}}{d \tau}+c_{s}\left(m_{r_{0}} W-\sum n_{i} M_{i}\right) \frac{d T_{s}}{d \tau}+ \\
& \left.+\omega_{s}\left(m_{r_{0}} W-\sum n_{i} M_{i}\right) \frac{d \omega_{s}}{d \tau}-\sum Q_{i} \frac{d n_{i}}{d \tau}-Q_{a d d}\right]
\end{aligned}
$$

The equation of the heat carrier flow velocity

The expression for determining the rate of the heat carrier flow was derived from the heat carrier mass flow equation:

$$
\mathrm{m}_{\mathrm{r}}=\rho_{\mathrm{r}} \omega_{\mathrm{r}} \mathrm{F},
$$

where $\rho_{\mathrm{r}}=\frac{1}{v_{\mathrm{r}}}-$ is the density of the heat carrier $\left(v_{\mathrm{r}}-\right.$ specific volume heat carrier) in the current section of the reactor; $F=\frac{\pi D_{p}^{2}}{4}=0.785 D_{p}^{2}$ - the cross sectional area of the reactor; $D_{p}-$ reactor diameter.

As a result of the conversion of the expression(16) we get:

$$
\omega_{\mathrm{r}}=\frac{\mathrm{m}_{\mathrm{r}} v_{\mathrm{r}}}{0.785 \mathrm{D}_{\mathrm{p}}^{2}} .
$$

After substituting the expression (14) into (17) and differentiating it we obtain the equation of the flow rate of the heat carrier:

$$
\frac{d \omega_{\mathrm{r}}}{\mathrm{d} \tau}=\frac{1}{0.785 \mathrm{D}_{\mathrm{p}}^{2}}\left[\left(\mathrm{~m}_{\mathrm{r}_{0}}+\sum \mathrm{n}_{\mathrm{i}} \mathrm{M}_{\mathrm{i}}\right) \frac{\mathrm{d} v_{\mathrm{r}}}{\mathrm{d} \tau}+v_{\mathrm{r}} \sum \mathrm{M}_{\mathrm{i}} \frac{\mathrm{dn}}{\mathrm{d} \tau}\right] .
$$

The equation of the change in the specific volume of the heat carrier

The specific volume of heat carrier in accordance with the principle of additivity is found from the relation:

$$
v_{\mathrm{r}}=\sum v_{\mathrm{i}} \mathrm{r}_{\mathrm{i}},
$$

where $v_{i}, r_{i}-$ respectively are the specific volume and the mole fraction of the $\mathrm{i}$-th component of the heat carrier in the current section of the reactor.

After differentiating the expression (19) we obtain the equation of the rate change of the heat carrier specific volume:

$$
\frac{d v_{r}}{d \tau}=\sum v_{i} \frac{d r_{i}}{d \tau}+\sum r_{i} \frac{d v_{i}}{d \tau} .
$$

The equation of the particle density change

When deriving the equation it is assumed that the particle density change during its heat treatment is due to burn out of the volatiles and carbon from its volume. The equation for determining the particle density is:

$$
\rho_{\mathrm{s}}=\frac{\mathrm{m}_{\mathrm{u}}}{\mathrm{V}_{\mathrm{s}}},
$$

where $V_{\mathrm{s}}$ and $\mathrm{m}_{\mathrm{Y}}$ - are the volume and mass of a particle in the current section of the reactor respectively.

The equation for determining the particle volume is:

$$
\mathrm{V}_{\mathrm{s}}=\frac{\pi \delta_{\mathrm{s}}^{3}}{6} \text {. }
$$

By substituting the equation (22) into (21) we get:

$$
\rho_{\mathrm{s}}=\frac{6 \mathrm{~m}_{\mathrm{u}}}{\pi \delta_{\mathrm{s}}^{3}} .
$$

The equation for finding the mass of the particle in the current section of the reactor is:

$$
\mathrm{m}_{\mathrm{u}}=\mathrm{m}_{\mathrm{u}_{0}}-\mathrm{m}_{л},
$$

where $\mathrm{m}_{\mathrm{y} 0}$ - the mass of the particle in the initial section of the reactor; $\mathrm{m}_{\mathrm{I}}$ - the mass of volatile components separated from a particle in the current section of the reactor in the process of its heat treatment.

$$
\mathrm{m}_{\mathrm{r}}=\frac{\mathrm{m}_{\mathrm{u}_{0}}}{\mathrm{~m}_{\mathrm{s}_{0}}}\left[\mathrm{n}_{1}^{0} \mathrm{M}_{1}-\left(\mathrm{n}_{1} \mathrm{M}_{1}+\mathrm{n}_{2} \mathrm{M}_{2}+\mathrm{n}_{3} \mathrm{M}_{3}+\mathrm{n}_{8} \mathrm{M}_{8}\right)\right],
$$

$M_{1}, M_{2}, M_{3}$ and $M_{8}-$ molar mass of components $n_{1}, n_{2}, n_{3}$ and $\mathrm{n}_{8}$.

The equation of a particle diameter change

After processing the data obtained during the study of photomicrographs of PPRH and $\mathrm{SiO}_{2}$ samples (Fig.3) an equation for determining the particle diameter in the current section of the reactor was offered:

$$
\delta_{\mathrm{s}}=\mathrm{A}+\mathrm{Bm}_{\mathrm{r}},
$$

where $\mathrm{A}$ and $\mathrm{B}$ - are the coefficients of the approximation. The values of coefficients A and B depending on the primary particle diameter are shown in Table. 3.

Table. 3. The values of coefficients A and B depending on the primary particle diameter

\begin{tabular}{|c|c|c|}
\hline $\begin{array}{c}\text { The primary PPRH particle diameter, } \\
\text { micron }\end{array}$ & $\mathrm{A} \cdot 10^{5}$ & $\mathrm{~B} \cdot 10^{5}$ \\
\hline 50 & 5 & $-3,14$ \\
\hline 100 & 10 & $-6,5$ \\
\hline 150 & 15 & $-9,43$ \\
\hline 200 & 20 & $-12,65$ \\
\hline
\end{tabular}

The equation for determining the amount of heat of the system

$$
\mathrm{Q}=\left(\mathrm{Q}_{\mathrm{C}} \mathrm{n}_{\mathrm{C}} \mathrm{M}_{\mathrm{C}}\right)+\left(\mathrm{Q}_{\mathrm{H}} \mathrm{n}_{\mathrm{H}} \mathrm{M}_{\mathrm{H}}\right)+\sum\left(\mathrm{n}_{\mathrm{i}} \mathrm{M}_{\mathrm{i}} \mathrm{c}_{\mathrm{p}_{\mathrm{j}}}\right) \mathrm{T}_{\mathrm{r}}+\mathrm{m}_{\mathrm{s}} \mathrm{c}_{\mathrm{p}_{\mathrm{s}}} \mathrm{T}_{\mathrm{s}},
$$

where $\mathrm{Q}_{\mathrm{C}}$ and $\mathrm{Q}_{\mathrm{H}}$ - the heat of combustion of carbon and 
hydrogen; $\mathrm{n}_{\mathrm{C}}$ и $\mathrm{n}_{\mathrm{H}}$ - the current number of moles of carbon and hydrogen; $n_{i}$ и $M_{i}$ - the current number of moles and the molar mass of the i-th gaseous component of the heat carrier; $\mathrm{c}_{\mathrm{p}_{\mathrm{j}}}$ and $\mathrm{c}_{\mathrm{p}_{\mathrm{s}}}$ - the current heat capacity of an i-th gaseous component and a particle respectively.

The heat capacity of a particle was calculated using the atomic heat capacity of elements in its structure:

$$
c_{p_{s}}=\frac{n_{C} C_{C}+n_{H} C_{H}+n_{O} C_{O}+n_{N} C_{N}+n_{S i} C_{S i}}{n_{C} A_{C}+n_{H} A_{H}+n_{O} A_{O}+n_{N} A_{N}+n_{S i} A_{S i}},
$$

where $n_{C}, n_{H}, n_{O}, n_{N}, n_{S i}$ - the number of atoms of carbon, hydrogen, oxygen, nitrogen and silicon that form the particle; $\mathrm{C}_{\mathrm{C}}, \mathrm{C}_{\mathrm{H}}, \mathrm{C}_{\mathrm{O}}, \mathrm{C}_{\mathrm{N}}, \mathrm{C}_{\mathrm{Si}}$ - atomic heat capacity of carbon, hydrogen, oxygen, nitrogen and silicon respectively; $\mathrm{A}_{\mathrm{C}}, \mathrm{A}_{\mathrm{H}}$, $\mathrm{A}_{\mathrm{O}}, \mathrm{A}_{\mathrm{N}}, \mathrm{A}_{\mathrm{Si}}$ - atomic weight of carbon, hydrogen, oxygen, nitrogen and silicon respectively.

The system of equations included in the mathematical model was carried out in a software environment MathCad by BDF method (backward differentiation formula) based on the use of formulas of reverse differentiation and designed for solving stiff systems of linear and nonlinear differential equations.

Initial parameters specified were: $\mathrm{W}$ - the ratio of the mass flow of particles to the mass flow rate of heat carrier supplied to the initial section of the reactor; $T_{\mathrm{s} 0}$ and $\mathrm{T}_{\mathrm{r} 0}-$ the initial temperature of the particles and the heat carrier; $\mathrm{w}_{\mathrm{s} 0}$ и $\mathrm{w}_{\mathrm{г} 0}-$ the initial velocity of the particles and the heat carrier respectively; $\rho_{\mathrm{s} 0}$ and $\delta_{\mathrm{s} 0}-$ the initial density and diameter of a particle; $v_{\mathrm{cm}}-$ specific volume of the heat carrier components mixture; $\mathrm{D}_{\mathrm{p}}$ - the diameter of the reactor.

Boundary conditions set were: the starting time $\tau_{0}=0 \mathrm{sec}$; the end of calculation - when the equality (29) is realized:

$$
\mathrm{n}_{\mathrm{SiO}_{2}(\mathrm{i})}-\mathrm{n}_{\mathrm{SiO}_{2}(\mathrm{i}-1)}=10^{-3} \text { moles, }
$$

where $\mathrm{n}_{\mathrm{SiO}_{2}(\mathrm{i})}$ - is the number of moles of $\mathrm{SiO}_{2}$ on the $\mathrm{i}$-th step of integration; $\mathrm{n}_{\mathrm{SiO}_{2}(\mathrm{i}-1)}$ - the number of moles of $\mathrm{SiO}_{2}$ in the previous step of the integration.

Solving the system of equations (1) - (27) there yielded relations of distribution of concentrations of the PPRH system components - the heat carrier in time (Fig.6) and influence of the mass ratio PPRH/heat carrier (Fig.7) on the amount of the heat energy of the system in the process of heat treatment of PPRH.

From Figure 6 it is clear that the process of transformation of PPRH into silicon(IV) oxide has 3 stages. The first stage proceeds with decomposition of PPRH and generating $n_{2}, n_{4}$ and $\mathrm{n}_{5}$. At the second stage - decomposition of $\mathrm{n}_{2}$ takes place forming $\mathrm{n}_{3}, \mathrm{n}_{5}$ and $\mathrm{n}_{7}$. At the third stage, $\mathrm{n}_{3}$ dissociates generating a solid target product $\mathrm{n}_{8}$ and gaseous $\mathrm{n}_{5}, \mathrm{n}_{6}$ and $\mathrm{n}_{7}$.

With the increase of the initial temperature of the heat carrier from $600^{\circ} \mathrm{C}$ (Fig.6.a) to $1000^{\circ} \mathrm{C}$ (Fig.6.b) the time of a complete transformation of PPRH into $\mathrm{SiO}_{2}$ decreases from 1900 to 240 seconds and the temperature of a particle reaches its maximum value of 520 and $830^{\circ} \mathrm{C}$ respectively.

From Figure 7 it is clear that at the change of weight ratio of $\mathrm{RH} /$ heat carrier from $1 / 2$ to $1 / 10$ the amount of thermal energy of the system remains constant and equal to $16 \mathrm{MJ} / \mathrm{kg}$ of $\mathrm{RH}$. When changing the mass ratio of $\mathrm{RH} /$ heat carrier in said changing within a heat release rate in accordance with the pattern of RH thermochemical conversion.
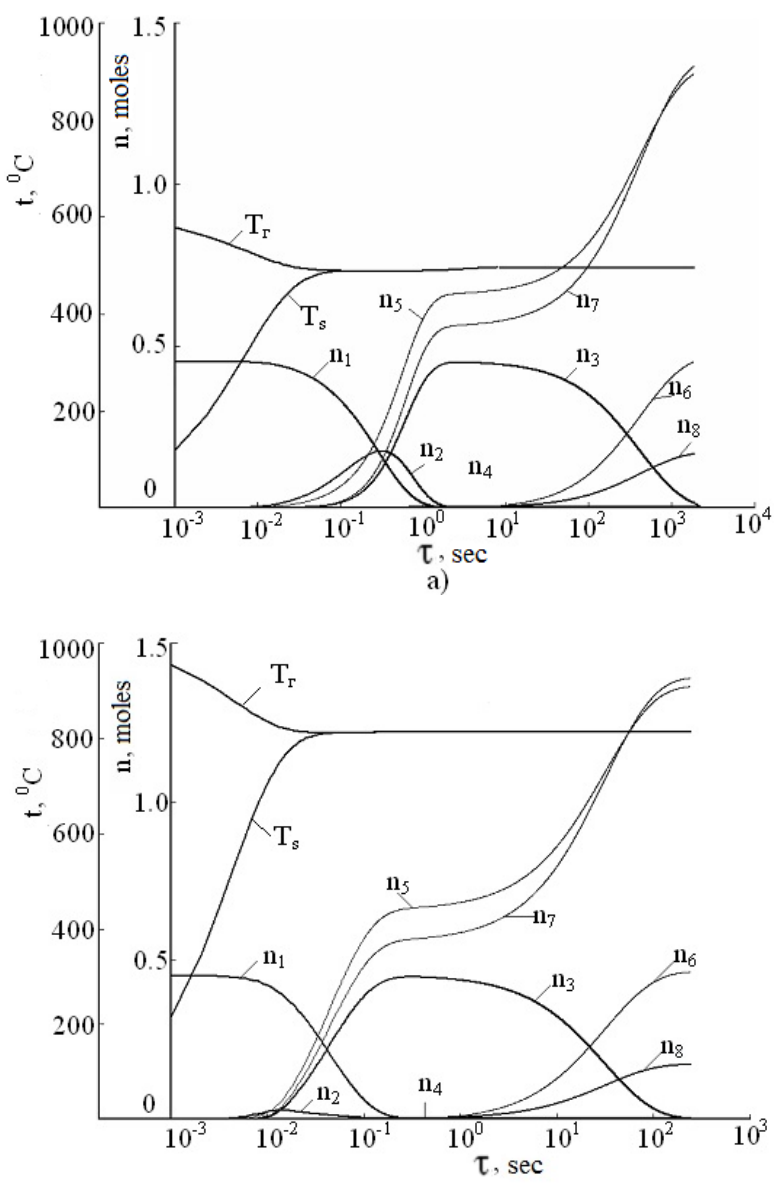

b)

Figure 6. The dependence of the concentrations distribution of components of the PPRSH - heat carrier system in time at $\mathrm{W}=1 / 5, \delta \mathrm{s} 0=50$ $\mu \mathrm{m}, \operatorname{ts} 0=27^{\circ} \mathrm{C}, \mathrm{ws} 0=0 \mathrm{~m} / \mathrm{sec}, \mathrm{Dp}=0,4 \mathrm{~m}, \operatorname{tr} 0=600$ (a), tr $0=1000^{\circ} \mathrm{C}(\mathrm{b})$

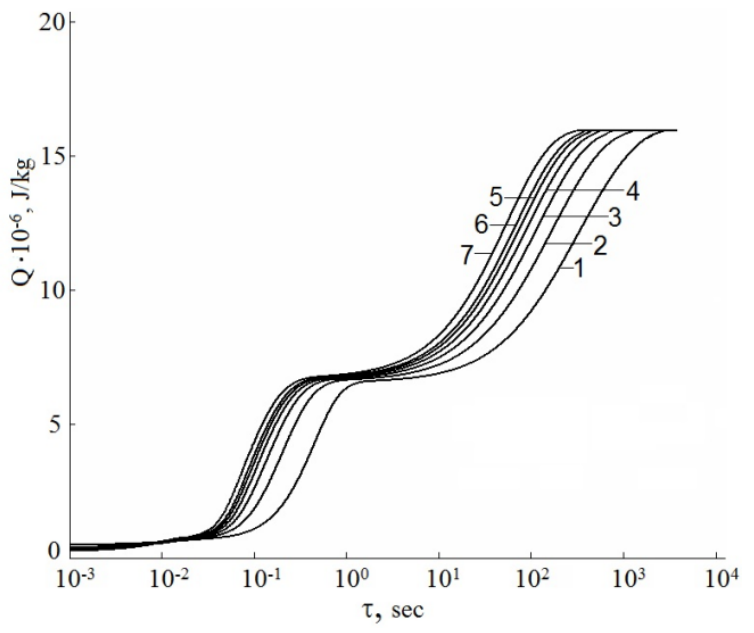

Figure 7. The change of the amount of heat energy during the heat treatment of PPRH in time at $\delta \mathrm{s} 0=50 \mu \mathrm{m} ; \mathrm{ts} 0=27^{\circ} \mathrm{C} ; \mathrm{ws} 0=0 \mathrm{~m} / \mathrm{sec} ; \mathrm{Dp}=$ $0,4 \mathrm{~m}, \mathrm{t} \Gamma 0=800^{\circ} \mathrm{C}, \mathrm{W}=1 / 2(1) ; 1 / 3(2) ; 1 / 4(3) ; 1 / 5(4) ; 1 / 6(5) ; 1 / 7(6) ; 1 / 10$ (7) 


\section{Conclusions}

1. A differential thermal analysis of the process of PPRH heat treatment was carried out and pre-exponential factors and activation energies of reactions of PPRH thermal transformation into silicon(IV) oxide were calculated.

2. Using XRD analysis of $\mathrm{SiO}_{2}$ patterns obtained from the heat treatment of PPRH at various temperatures, phase composition were studied, and it was defined that when carrying out the process of PPRH heat treatment in the temperature range of $500-900^{\circ} \mathrm{C}$, the obtained product is amorphous. When carrying out the process of PPRH heat treatment at a temperature above $1000^{\circ} \mathrm{C}$ the obtained product has a crystalline structure.

3. After studying the photomicrographs of PPRSH particles and particles of $\mathrm{SiO}_{2}$ obtained by PPRH heat treatment it was found that the particle diameter decreases in the range of $45-50 \%$ of its initial diameter.

4. A mechanism of the process of thermal transformation of PPRH into silicon(IV) oxide was offered, and based on this mechanism equations of the chemical kinetics of the process were compiled.

5. A mathematical model of the a combined process of obtaining heat and silicon(IV) oxide was developed involving the equations of heat and mass transfer, gas dynamics and the equations of chemical kinetics of the process.

6. It was defined that when increasing the initial temperature of the heat carrier from 600 to $1000^{\circ} \mathrm{C}$ with all other conditions being equal the time of a complete transformation of PPRH into $\mathrm{SiO}_{2}$ decreases from 1900 to 240 seconds. As we can see from Figure 6. a. b. out of 0.452 moles of PPRH it's produced 0.171 moles of $\mathrm{SiO}_{2}$ which is equivalent to $0,205 \mathrm{~kg}$ $\mathrm{SiO}_{2}$ out of $1 \mathrm{~kg}$ of PPRH.

7. It was established that when the weight ratio of RH / heat carrier changes from $1 / 2$ to $1 / 10$ the amount of heat energy released during the heat treatment of $\mathrm{PPRH}$ is $16 \mathrm{MJ} / \mathrm{kg}$ of PPRH.

\section{REFERENCES}

[1] Rice, milled // electronic information and analytical magazine "AgroChart". URL: http://www.agrochart.com/ru/statistic/pr oducts/product/127/section/56

[2] Record cereal production to ease tight supplies in $2013 / 14$ //Food and Agriculture Organization of the United Nation 05. Sept. 2013 URL: http://www.apk-inform.com/ru/exclusive/t opic/1010844

[3] Sergienko V.I., Zemnuhova L.A., Egorov A.G. /Renewable sources of chemical raw materials: a comprehensive waste processing of rice and buckwheat// Rossiyskiy himicheskyiy zhurnal. - 2004, Vol. XLVIII., No 3., 113 - 124.

[4] Belaya A.A., Gridneva T.V., Tertyishnyiy O.A., Soroka P.I. /The energy efficiency of processes for obtaining siliceous materials from rice husk// Naukovi pratsi Odeskoyi Natsionalnoyi akademiyi harchovyh tehnologiy. - 2009, Vol. 2, No 35, P. $200-203$.

[5] Pat. 2233795 RU, IPC C01B 33/12, F23C 9/00. Method of obtaining silica from rice production wastes and device for its implementation / Dobrojanskyi V.G., Zemnuhova L.A., Sergienko V.I. - № 2003125691/15, Decl. 20.08.2003, Publ. 10.08.2004, Bul. № 16 .

[6] Pat. 2291105 RU, IPC C01B 33/12, F23C 9/00. method of obtaining silica and heat energy from plant siliceous wastes and device for combustion finely divided materials / Skryabin A.A., Sidorov A.M., Puzyrev E.M., Schurenko V.P. - № 2005127829/15, Decl. 06.09.2005, Publ. 10.01.2007, Bul. № 1.

[7] Soroka P.I., Tertyishnyiy O.A., Smirnova E.S., Gridneva T. V. /Obtaining of silicon compounds from rise waste production/ Voprosy himii i himicheskoy tehnologii. -2006 , Vol. 2, No 28, P. 4-10.

[8] Pat. 88748 UA, IPC C01B 33/12. Method for obtaining silicon dioxide from rice husk/ Soroka P.G., Gridneva T.V., Tertishniy O.O. - № a200813731, Decl. 28.11.2008, Publ. 10.11.2009, Bul. № 21 .

[9] Pat. 96082 UA, MPK V02S 13/14. Centrifugal impact mill/ Soroka P.G., Oparin S.O. - № a201006351, Decl. 25.05.2010, Publ. 26.09.2011, Bul. № 18.

[10] A.V. Obolenskaya, Z.P. Elnitskaya, A.A. Leonovich. Laboratory work on the chemistry of wood and cellulose: Textbook for high schools - M.: "Ekologiya", 1991. - 320 p.

[11] A.A.Zharmenov, S.V.Efremova, Yu.I.Suharnikova/Mechani sm of thermo-chemical transformation of rice husks at the thermal treatment/ Vestnik KazNU.-2012, Vol 2, No 66, P. 73-83.

[12] Powder diffraction tile. Alphabetical index inorganic phases. - USA: JCPDS Int. Cent. for diffraction data, 1989. - 1023 p.

[13] Hugh H. Horwitz and Gershon Metzger /A new analysis of thermogravimetric traces// Analytical chemistry.- 1963, No 9, P.1464-1468

[14] Gridneva T.V., Belaya A.A., Soroka P.I., Tertyishnyiy O.A., Volkova S.A. /The kinetics studying of the process for obtaining siliceous compounds from rice husk// Naukovi pratsi Odeskoyi Natsionalnoyi akademiyi harchovyh tehnologiy. - 2010, Vol. 2, № 37, P.4-8.

[15] V.D. Parhomenko, P.I. Soroka, L.A. Golubkov, P.V. Lipatov. Preparation of ferrite powder in a high temperature carrier streams. - K.: Naukova dumka, 1988-152 p.

[16] Keveno L.L. / Heat transfer in the areas of rarefied gas flow subsonic// Mehanika. - 1956, No 6, P. 27 - 38.

[17] Heat and Mass Transfer: directory /Edited by Lyikov A. V.// M.: Energiya, 1971. -560 p. 